\title{
'Sis Science' and Fitness Doping: Ethnopharmacology, Gender and Risk
}

\author{
Ellen Sverkersson ${ }^{1, *(D)}$, Jesper Andreasson ${ }^{1}$ (D) and Thomas Johansson ${ }^{2}$ (D) \\ 1 Department of Sport Science, Faculty of Social Sciences, Linnaeus University, 39182 Kalmar, 35195 Växjö, \\ Sweden; jesper.andreasson@lnu.se \\ 2 Department of Education, Communication and Learning, University of Gothenburg, Box 300, \\ 40530 Göteborg, Sweden; thomas.Johansson@ped.gu.se \\ * Correspondence: ellen.sverkersson@lnu.se
}

Received: 18 March 2020; Accepted: 17 April 2020; Published: 21 April 2020

check for updates

\begin{abstract}
This article is part of a larger investigation looking into recent changes in the demographics of fitness doping and the possible consequences of such changes. Contesting the historical alliance between masculinity and fitness doping, the article focuses on women's narratives and experiences of fitness doping in a male-dominated open online community called Flashback. The article builds upon a qualitative and netnographic approach to the research. Employing the lens of the potential emergence of a woman-based ethnopharmacological culture, this article investigates the ways in which women talk about and rationalise their use of performance and image enhancing drugs (PEIDs), their potency and potential gendered side-effects. The results show that although fitness doping can be largely understood in terms of hegemonic patterns, women have gained ground in the context of online fitness doping, heralding a changing doping demography and a movement towards a 'sis science' ethnopharmacology. Although critiqued by men, the context enables women to freely discuss harm reduction, risks and the potential potencies of various drugs, and to share knowledge that is relevant to female biology and discuss their own experiences, an activity that also makes visible the negotiation of new gender positions.
\end{abstract}

Keywords: fitness; doping; body; gender; side-effects; ethnopharmacology; women

\section{Introduction}

Due to technological development in recent decades, it is not surprising that different forms of online communities and forums have become arenas that encourage sensitive content to be expressed, without compromising confidentiality (Adler and Adler 2011; Smith and Stewart 2012). Several studies have shown how people have constructed a myriad of online communities that enable them to interact with others while learning about different illicit substances, such as performance and image enhancing drugs (PEIDs), their effects, and the risks associated with their use (Belenko et al. 2009; Murguía et al. 2007). Having studied the social mechanisms involved in online community trust, Bilgrei 2018, for example, shows how community members' reported personal experience of drug use may form the basis of drug-using lifestyles and experiential learning among online community members. This is referred to as 'broscience', a portmanteau of 'brother' and 'science', which concerns the knowledge that is maintained, contested and passed on by users (p. 2713). What is being described here is thus a form of ethnopharmacological subculture infused with gendered understandings (cf., Monaghan 2001), where predominantly male users interact with one another and share their experiences of using drugs, drug side-effects, courses of drugs, risks associated with drug use, and more, while also expressing distrust of medical experts and authorities, who are perceived as lacking real first-hand specialist knowledge (see also Sumnall et al. 2011; Andreasson and Thomas 2016). 
Applied to fitness doping, the term broscience would suggest that knowledge and experiences of PEIDs is mainly to be understood as something male-connoted, simultaneously backgrounding women's experience and voices. Although fitness doping can still be understood in terms of hegemonic patterns - with men dominating the scene and setting the agenda for fitness doping-studies indicate a growing trend of women gradually becoming integrated into online communities where PIED use is discussed and debated (Andreasson and Thomas 2020; Henning and Andreasson 2019). This raises questions concerning a possible sis science in the realm of fitness doping and ethnopharmacological knowledge in online cultures. Contesting the alliance between masculinity and fitness doping, introducing women as active users, and exploring the ongoing gender-bending present in fitness culture, the development of a sis science also would indicate that women are not exclusively relegated to men's knowledge and experiences to access personal accounts of the use of performance-enhancing drugs and more authoritative information about such drugs (Monaghan 2012). At the same time, gender transgressions rarely stay unnoticed, and women's boundary-crossing into the realm of muscular masculinity, through drug-use practices, has often been met with criticism and considered a threat to the 'natural' order of things (Aoki 1996; Richardson 2008; Washington and Economides 2016).

Expressions of an ethnopharmacological doping subculture on the Internet, and its gendered connotations (broscience/sis science), come with certain risks and dangers, of course. On the one hand, mentors and advisors are easily available on different chat groups and forums. On the other, there is a minimum of control and risk analysis. The subcultural phenomenon of bodybuilding, with its one-sided and sometimes naïve glorification of PIEDs, is in a certain sense brought closer to 'ordinary people'. The tremendous development of gym and fitness culture in combination with the possibilities brought by the surge in technological development-whereby Internet-based communication facilitates instant information without comprising confidentiality—has in a way brought subcultural phenomena together with more general cultural phenomena. In this mixture of different perspectives-on training schedules, diet, gender, drugs and body ideals—a new fitness-doping phenomenon has emerged and a new fitness-doping demography is taking shape (Bates and McVeigh 2016).

Following this line of thought, this article takes a netnographic approach to the research, aiming to zoom in on significant changes in the demographics of fitness-doping and the possible consequences of such changes. In the article, we will focus on women's narratives of fitness doping in an open online community called Flashback. Describing itself as "Sweden's largest forum for freedom of expression, opinion and independent thinking" (Flashback n.d.), this forum may be considered a highly open-minded community as regards prohibited activities, such as the use of PIEDs. This does not mean, however, that the forum is equally open-minded as regards the gendered dimensions of fitness doping and the ways in which PIED use is discussed and legitimised. Therefore, what we are interested in is finding out if it is possible to talk about the development of a 'sis science' -an ethnopharmacological subculture of female fitness dopers. More precisely, this article aims to investigate the ways in which women on Flashback talk about and rationalise their use of PEIDs, the potency of the drugs and their possible (gendered) side-effects.

\section{Background and Survey of The Field}

Outside the sphere of organised sport, research on doping has largely been a story about men, muscles and masculinity (Klein 1993; Monaghan 2001, 2012; Denham 2008; Liokaftos 2019; Christiansen 2018). Research has also shown that, in the western world, the use of PIEDs within the context of gym and fitness is more common among men than women (Breivik et al. 2009; Sagoe et al. 2014; Christiansen 2018). Nevertheless, the fitness geography is gradually changing, and so are the demographics of doping (Van Hout and Kean 2015; Coomber et al. 2015). Boosted by an increasing preoccupation with body image issues among both men and women (Cash and Pruzinsky 2002), women have gradually entered the realm of fitness doping (Grogan et al. 2004; McGrath and Chananie-Hill 2009; Jespersen 2012; Van Hout and Hearne 2016). Due to the widespread availability of PIEDs and their growing prevalence among mainstream fitness groups, 
including women, it is therefore possible to talk about an emergent public health issue (Van Hout and Hearne 2016; Christiansen 2018).

Research show that PIED use differs by gender (Klein 1993; Sagoe et al. 2014; Brennan et al. 2017). Due to the association between muscles and masculinity, women have tended to use drugs considered 'less masculine', such as human growth hormones (HGH), ephedrine and clenbuterol, as opposed to muscle-enhancing supplements, such as anabolic androgenic steroids (Jespersen 2012). Of course, the diversification of the gendered dimensions of drug use also corresponds to the anticipated and gendered side-effects associated with the various substances.

Due to social disapprobation of fitness doping (Roussel et al. 2010), and legislation prohibiting the use of PIEDs, such as in Sweden, it is not surprising that those seeking information or wishing to share and discuss their expertise and experience with PIEDs turn to online forums (Henning and Andreasson 2019). The online path to learning about and potentially entering the doping experience exists in a context that is not bound by national laws, policies, or prevention strategies. Of course, this has had a great impact on the face of fitness doping. Face-to-face encounters have been partly replaced by online interactions, making available a myriad of voices ready to guide new users, both male and female, young and old, into the practice. In a certain sense, what we are seeing is the evolution of new forms of ethnopharmacological learning processes and cultures. However, while men have had access to online forums and subcultural settings in which PIED use is discussed for some time (Smith and Stewart 2012; Monaghan 2012), women have largely been left out of the equation regarding such social communities (Roussel and Griffet 2000; Thualagant 2012; Van Hout and Hearne 2016). Bunsell (2013) discusses this in terms of a 'veil of secrecy' and a 'taboo', through which women's experiences have come to be understood as bound to others (read: men) guiding them. Despite the lack of research on women's (online) fitness doping experiences, women are engaging in the practice, and in seeking out advice, like men, they may use online forums as sources of information.

\section{Analytical Framework: Contesting the Male Hegemony}

This article is situated in body studies, with a specific focus on gender and the transgression of traditional gender hierarchies (Blackman 2008; Demello 2014). In our analysis, we are interested in what happens when women gradually enter the male-connoted world of fitness doping in order to gain information and become part of an ethnopharmacological subculture. Challenging the male dominance and hegemonic understandings of what it means to be a user of PEID, women inhabit an ambivalent position. We will use Turner (1969) description of liminality to capture this positioning.

Liminal entities are neither here nor there; they are betwixt and between positions assigned and arrayed by law, custom, convention, and ceremonial. As such, their ambiguous and indeterminate attributes are expressed by a rich variety of symbols in the many societies that ritualize social and cultural transitions.

(p. 95)

Looking at gendered identities as processes and as gradual incorporations of old and new ways of doing gender fits nicely into our aim and our perspective on the construction of doped bodies. The ritualistic components of the creation of these bodies, as well as the liminal states achieved during the disciplined training schedules, will enable us to gain new knowledge about how the women move between their goals and fantasies of perfection, ethnopharmacological knowledge, medicalisation, and thoughts about the potency of the drugs and their potential (unwanted) side-effects.

To meet these changes in the development of a new fitness doping demography, we would like to suggest a re-articulation of hegemonic masculinity, breaking with Connell's notion of hegemonic masculinity as always being defined in opposition to 'emphasised femininity'. This is a term chosen deliberately to fix femininity — even in theory—as being always subjugated to masculinity (Connell and Messerschmidt 2005). If we break this connection, we might well argue that what hegemonic masculinity represents is not a discourse that ultimately always works to subjugate women/femininity. 
What we must also break with then is the notion that all forms of hegemony are equally bad and that the ultimate goal of emancipatory struggle must be to do away with hegemony. What we need to do is to try to disentangle the notion of hegemony from a taken-for-granted connection to some specific form of masculinity and femininity (Johansson and Ottemo 2015). In doing so, fitness doping can be reconceptualised, that is, understood less in terms of stereotypical gender configurations and more in terms of issues concerning health and the development of certain lifestyles. This will be further discussed in the findings section.

\section{Methodology and Methods}

This article is part of a larger ethnographic and netnographic investigation into fitness doping (see for example Andreasson and Thomas 2020). In this study, however, we have chosen to direct and limit the focus of our attention to an online forum and community called Flashback. This forum is hosted in Sweden, and although there are occasional contributions posted in English, Danish or Norwegian, most of the postings are in Swedish. On Flashback, anyone with an Internet connection can read different postings, and if creating an account with a fictive username one can also start up different threads and engage in discussions with other community members on a wide variety of topics. Discussions can concern basically just about anything, such as gardening, culture, travel, sex and more. Since the forum facilitates the expression of opinions anonymously, however, quite a few discussions concern prohibited practices. One popular theme on which we find thousands of threads concerns doping. While the personal information presented is limited, many of the posts are made by men; at the same time, there are also women participating in discussions about doping.

When conducting the study, we employed the method of netnography, which has been specifically designed for studying online cultures and communities. Developed by Kozinets, 2010, netnography is methodologically indebted to the traditions and practices of ethnography and is sometimes also referred to as online ethnography (Hine 2000; Kozinets 2010). We have focused on discussions/threads published on Flashback, taking the perspective that these are to be understood as important parts of human experience (Garcia et al. 2009). What we have done is follow female community members on Flashback over time, analysing their ways of discussing doping in the context of online communication. As suggested by Kozinets (2010, p. 22) technology is understood as something that "constantly shapes and reshapes our bodies, our places, and our identities, and is shaped to our needs as well." This means that when women engage in discussions on Flashback, they gradually learn about drug use practices-they ask and answer questions and in so doing contribute to the formulation of ideals and identity positions that include certain gender configurations.

Doing netnography as well as ethnography requires the researcher to engage and spend time in the community where the research takes place, to gain knowledge about the culture and the individuals acting within it (Berg 2015; Bertilsson 2014; Kozinets 2015). In this study, we read the ongoing discussions on Flashback daily for eight months, to familiarise ourselves with the community, particularly the women interacting within it. In selecting data for the study, we focused on postings in which it was indicated explicitly that it was a woman behind the anonymous username used. As researchers, we adopted the role of passive participants, that is, we chose not to interact or influence the discussions that took place. In the sampling process, using keywords such as 'women' and 'girls', we initially found 445 unique threads on Flashback in which doping was discussed. Out of these, it was possible to identify 51 threads that were initiated by a female community member. Initially, these 51 threads were downloaded to a secured disk and copied to a Word document. The threads varied in length and number of comment posts (stretching from 1 to 194 comments/posts). The transcripts of the threads were read repeatedly and coded into themes that responded to the more theoretically informed purpose of the study and could capture the subjective meanings being expressed regarding female fitness doping (cf., Aspers 2011). The coding was conducted manually and initiated inductively. Gradually developing our understanding of the data and the emerging focus of attention in our themes, we could successively refine our research focus (Kozinets 2010, p. 119). Theoretically informed 
notes were made during this process in order to contextualise the excerpts in terms of particular aspects, such as gender, side-effects, medicalisation, and health. Moving between empirical data and theoretical and analytical tools, we looked for excerpts that provided insight-in a nuanced way-into the ways in which the use of PEIDs was conceptualised and understood as an integral part of the women's experiences.

In order to secure the identity of the community members quoted, certain measures to protect their anonymity were taken. Firstly, all of the women quoted have been given fictitious usernames. Secondly, the original postings were in Swedish; they have been translated into English here, which makes it impossible to use existing search engine technology to trace a member through a posting. Formal ethical approval has been secured from the Regional Ethical Review Board of the University of Linköping in Sweden (Ref. No. 2017/468-31).

\section{Findings}

\subsection{Ethnopharmacology and the Medical Gaze}

On Flashback, there is a wide variety of explanations put forward regarding people's reasons for engaging in fitness doping. While some women describe themselves as dedicated fitness competitors or bodybuilders, others talk about doping in terms of increased well-being and/or a way of getting in shape (cf., Christiansen et al. 2017). Despite this variety, however, one commonality among the women is an expressed eagerness to change the body and its composition by means of PIEDs. One community member exemplifies this, and in doing so she also initiates a discussion on how one should start taking the drugs:

After considerable research, reading scientific results, and gathering information on different Internet forums, I've decided to do a DNP course, to be able to remove the last kilos stuck on my stomach and thighs, which are really hard to remove for girls, you know. I have not found any evidence at all that one can become sterile-and when asking people on the forum, no one can support this statement-So, I'm going to do it.

(DidMyHomework)

Engaging in fitness doping means engaging in something unfamiliar. Although the above excerpt shows a high level of knowledge-seeking, through which DidMyHomework has tried to inform herself about the use of 2.4-dinitrophenol (DNP) - a cytotoxin that increases body temperature and thus speeds up fat-burning processes-she still asks others for advice. She makes sure to explain that she has done her homework, and that her decision is informed and was made in relation to available scientific knowledge. Thus, what she is seemingly aiming for is to present a rationale for her intended use and legitimise it. At the same time, 2.4-DNP is not classified as a drug per se in Sweden, but rather as a toxic substance used for different purposes, such as wood preservation, dyeing preparations and making explosives (Personne et al. 2014; Sousa et al. 2020). Consequently, the use of this drug could bring severe harm, to say the least, which also makes the discouragement that DidMyHomework receives quite reasonable. Nevertheless, mirroring Monaghan, 2002, what the excerpt exemplifies is a desire to obtain information about and experiment with different substances, which is part of an ethnopharmacological online subculture. DidMyHomework initiates her discussion of courses and substances and presents an idea or theory about anticipated side-effects. In relation to others who engage in the same thread, a doping taxonomy is gradually taking shape. Another community member talks about her intended use, thus also providing insight into the ways in which this ethnopharmacological subculture and taxonomy may manifest:

I am planning a six-week course on $5 \mathrm{mg}$ Tbol (Turinabol). I'm a woman in her thirties, and I have a good track on my training schedule. My goal is to build more muscles and lose some fat, although fat loss is secondary. I will continue to eat clean food, and my goal is to have an intake of at least 2-2.5 milligrams of protein per kilogram of body weight. I will 
probably achieve a calorie balance. My training should continue the way it is right now, that is, strength training 4 or 5 times a week, and two cardio workouts also / . . / Primarily, I'm worrying about body lipids. Off-the-cut, I don't think it's logical to assume that I could reach a dangerous level on such low dosages. Men usually take much higher dosages, and they do fine.

\section{(MsShape)}

In the above excerpt, MsShape is not only negotiating training goals and lifestyle choices; she is also explaining how to balance these with physiological reactions and medical conditions that could occur with a course of steroids (Tbol/Turinabol). When discussing her use of PEIDs, she is showing a high level of reflexivity, and is seemingly also aware of the potential risks involved in taking these drugs (we will return to the possible side-effects in the third section of the findings). Still, she is determined to carry on. Through various sources, particularly the Internet, she is searching for information on how to understand and deal with the possible consequences of her lifestyle choices. She is thus engaging in a learning process, reflecting a harm reduction perspective. In addition-and of relevance here is the fact that she is using a male doping user as a reference point-she is downplaying the extent of her own use. She is unsure about the significance of sex and the impact the drugs may have on the female body, especially in comparison with a male body. This is also discussed by others. Below, one woman responds to a male member who has criticised her for using 2.4-DNP, telling her that she will probably not be able to have children later in life. She responds:

So, you think I'm stupid, and then you don't expect a reaction? And, yes, I've read a lot, and I have female friends who've done several courses of DNP, and have been able to give birth later. So, it's really exaggerated. Probably there were some girl, a long time ago, who did a course while pregnant, and she lost her child, which could happen, of course.

(NotStupid)

NotStupid tries to negotiate and understand the gendered dimensions of the ethnopharmacological subculture on Flashback. She is aware that the community is male-dominated and is prepared for being questioned by men. What she encounters is claims that she considers are based on misinformation and not convincingly backed by science (Bilgrei 2018). What she touches on is a perceived male bias in the ethnopharmacological discussions developing on Flashback. It is also obvious that the available information seems to be mainly oriented towards male users, their experiences and their bodies. This is sometimes seen as problematic.

It's such a shame that there's no research, no "guidelines" and no good place with overall knowledge from girls who have used. So, it's very difficult to know how to do it. / . . / That's why I started this journal (course reports). If I'm open about my course and my perceived side-effects, maybe it can help someone else.

(NoGuidelines)

There is still not that much available information or knowledge about medical conditions related to drug use among women on Flashback. There are, however, women who are looking for tips about suitable preparations, who also want to read about the experiences of other women. Several of the women who share information about their courses, on the subtheme course reports on Flashback, are mainly addressing other women who are interested in gaining more knowledge. What we see here is thus the gradual development of a medical gaze through which the women discuss and analyse the possible effects of different PIEDs. As shown, the development of this gaze and the ethnopharmacological culture also brings a certain amount of 'mansplaining' that the women need to deal with. In a way, the medical gaze developed can be understood also as a hegemonic masculine gaze. Women's experiences are met and judged in relation to men's knowledge, and their dosages are likewise compared to the body of a man. It is probably reasonable, however, to talk about an 
evolving fitness doping sis science focusing on PEID experiences relating specifically to the female body. However, when women try to discuss their doping taxonomies and ideas, they are still not always taken seriously.

\subsection{Side-Effects and Gender Risk Management}

Historically, western society has viewed men and women as biological opposites (Johansson 1998). On Flashback, women seem to be keen to position themselves as women in order to obtain feedback relevant to their biology. A discussion initiated in the previous section suggests that, when approaching the body and the possible side-effects of PEIDs, there is a need for other women's perspectives and experiences. A doped man's body cannot be understood or analysed in the same way as a doped woman's body. One community member explains:

As a woman, there is always a bigger risk. I know it's easy to look at the guys' dosages and laugh at your own, but it's impossible to compare the two.

(UniqueQ)

In the pursuit of the ideal body, there is a desire to reach the goal through systematic body control, diet, exercise, preparations and drug regimes. Many women perceive the body as a project, but its biological functions are hard to fully control while using PEIDs. The women know that their bodies differ from men's, and that they have to adjust dosages and choices of drugs in order to get the desired results and cope with the possible side-effects. Instances of women describing their PIED consumption in relation to men's were not uncommon. The male body is understood as something of a yardstick for adjusting dosages and anticipations. The women tend to describe how they engage in milder or lower dosages or "girl dosages", which also is a way of legitimising their PEID use. Seemingly, they are not pursuing the extreme muscular body, but rather a slim, toned and slightly muscular body (Boepple et al. 2016). NoTesto explain:

If you want to keep your femininity and not be transformed into a man, then "testo" (testosterone-based substances, authors note) is not an option, and there aren't many drugs that allow you to keep your femininity. Primobolan is a good option for that matter. I haven't experienced any unpleasant sideeffects of 'primo' and it is considered to be a relatively 'mild' steroid. Considering this, I see no reason not to use Primo over a longer period.

(NoTesto)

In the excerpt, NoTesto addresses issues broached by other women about finding appropriate drugs to improve muscle growth. She shares her experience of doping and informs other members of her knowledge. Her posting also highlights a common fear among the women discussing doping on Flashback, namely that they could end up with side-effects in the form of physical attributes commonly associated with men and masculinity (McGrath and Chananie-Hill 2009). Such side-effects-often gender-coded and visible side-effects, such as increased body hair, an enlarged clitoris, a deeper voice, etc. (Börjesson et al. 2016) —are described as worse than other side-effects that are not aesthetically associated with men or masculinity. Another community member describes her experience of a six-week course on Anavar (Oxandrolone) and Ephedrine. After finishing her course, she reflects on the outcomes of her course and what it resulted in.

The differences that I noticed were an incredible fatigue and that the hair on my legs and underarms grew faster. I had to shave and use a depilatory more often. Also, I had to fix my eyebrows more often, but luckily, hair did not grow in new places. I did get more acne, some on the shoulders and a few pimples in the face. Got a little vocal hoarseness-not a man's voice; more like sexy voice-and, not to forget, a more sensitive clit. I think it was during the fourth or fifth week. But all the side-effects disappeared quite quickly after I finished my course. I have had some problems with my joints, but that was a problem even before I did any doping. I was terrified of side-effects and decided to stop using immediately if I 
noticed something wrong. I think it's a little embarrassing to talk about it-although my side-effects were transient, it feels private. I think it's uncomfortable to read about other people's side-effects, but it's important to get information from other users, especially when reading about different drugs. After completing the course, I didn't feel masculine at all; on the contrary, I felt more feminine. If you do your research and stick to low doses-and as a girl use Anavar, for example-I think the risks of having side-effects are small. But everyone's different and there are no guarantees.

\section{(CautionUse)}

Like other women, CautionUse experienced some side-effects following her use of Anavar. She cultivates for her feminine presentation by shaving her body and getting her eyebrows done more often, and by re-coding some of the side-effects into more female expressions. She is practicing control over her side-effects while also negotiating and re-evaluating gendered liminalities and conceptions of male and female bodies. In addition, she emphasises the importance of knowledge and body awareness. Caution Use is not the only one negotiating and re-coding the results of her course. Some of the women report a lack of menstruation and an enlarged clitoris-while obviously side-effects of the drugs-as welcome rather than unwelcome side-effects, which can be interpreted as a desire to negotiate a liminal body in transformation without contesting what is considered to be a feminine identity. Although CautionUse feels a bit uncomfortable sharing her experience, she affirms the necessity of women participating in online knowledge diffusion concerning PEID use. Possible (negative) side-effects and risks are thus being discussed among women on Flashback, although not all course reports are completed.

Another community member, WhatToDO, describes her side-effects and asks others for advice and guidance while simultaneously trying to serve as a cautionary example of what could happen if one is not careful.

First and foremost, I just want to warn girls who are thinking about using AAS (Anabolic-Androgenic Steroids). As you may realise, I have used it myself and experienced almost every side-effect you can get. My question is: Will the side-effects disappear with time? I have stopped using the steroids. I got these side-effects: deep voice (I sound like a man), intense hair growth all over my body, a moustache and a beard, and male facial features. My menstruation has disappeared, my body looks more like a man's, my metabolism is disturbed (I can't eat normally and I've put on a lot of weight), and I have high blood pressure and acne. Which of these side effects are permanent and which ones will disappear?

\section{(WhatToDO)}

What ToDO receives many answers. Other community members of both sexes even give her advice about taking cortisone and estrogen, getting laser treatments for unwanted hair, and more. When the body does not respond in a desirable way, we are deprived of power over the body and lose our ability to achieve desirable body ideals (Sveen 2000). WhatToDO, unlike CautionUse, seems to cross a line where it is no longer possible to re-code what is considered to be stereotypical male expressions into femininity. To regain control over her body and counter gender stigmatisation, she uses the forum to solicit others' advice and learn about drugs to help with her weight problem. Like other women who encounter unwanted side-effects of PEID use, she is questioned in the thread as to her level of awareness. Hence, the side-effects are mainly seen as the result of a lack of control, in terms of incorrect dosages and choices of drugs.

The transformation of the body into something highly desired comes with a (potential) price. Body management becomes a central issue in everyday life. While the drugs lead to improvements and muscular development, they also have a negative impact on the physiology of the body. It becomes crucial to monitor and regulate the body and reduce the side-effects. In many cases, risk management and the development of a medical gaze seem to work to a certain extent, but not completely. Flashback 
is a place where, in the context of side-effects, female identities are negotiated, shaped and reshaped-it is a community where doping experiences are shared, studied and sometimes questioned. It is also a source of warnings and discouragement, such as when something has gone wrong and there is a need for help and support. In the discussions among female community members, the question of side-effects is a hot topic. Problems with rashes, menstrual cycles, libido, stretch marks, fertility, mental health and potentially masculinising effects are often touched on (see also Evans-Brown et al. 2012; Rasmussen et al. 2016). But so is the potential for positive outcomes and the potency of the drugs. This will be further developed in the next section.

\subsection{Potensification of the Doped Body}

Although the women are aware of the risks involved, they are also constantly analysing and working hard to reduce their side-effects, as discussed in previous section. Risk management and harm reduction seem to be an important part of engaging with this ethnopharmacological online subculture. In the next excerpt, however, we will examine some of the side-effects described and discussed on Flashback that are not seen as unwanted, but rather as connected to satisfaction and ideas about the body beautiful.

Hello, Hello!

Now it's time to initiate this long-awaited course. Starting next week. I'm super excited!!!!! I'll go for $2.5 \mathrm{mg}$ of Anavar to start with, but I think that'll be good enough. Time will tell. This is my first time, so it'll be interesting. I have expectations, but not too high ones, hopefully. I might not respond to the drugs sufficiently so of course I may go off them soon- also because I'm female. But fingers crossed! And you must keep yours crossed too, guys, and especially women. If you have any tips or tricks, or anything else to say for that matter, speak now for God's sake! I'm in the process of preparing my muscles for hard work, although not as heavy as when I start the course. Then I'm gonna pump the iron for sure.

(PumpItUp)

The fear of masculinisation is clearly an issue for the women, but at the same time there is also evidence to support a potensification of the doped body. We will use this term/concept to suggest an affirmation of desires and dreams, sometimes even sexual ones, connected to the women's narratives of their PEID use. Clearly, as discussed in the previous section, there are ideas being discussed about side-effects that are typical for a woman's body. But in relation to this ethnopharmacological culture, there is also discussion about other topics, such as health and well-being generally. One community member explains:

One more thing. The drugs are not happy pills, but generally I felt great; despite my terrible overdosage of 'wins' (Winstrol). This course should really be combined with an 'anti-horny pill', though. Take care.

\section{(Happy)}

Discussions about feeling satisfied and pleased with life when on a course occur in several threads. Sometimes this are combined with more explicit discussions about sexual desires and sexual daydreams. The topic of female sexuality is not avoided here, but rather expressed and accentuated as something positive-as a potensification of the self. In the next excerpt, DemandingLady expresses her strong desires and heightened sense of longing for sex and sexual encounters.

I'm back, I'm stable, and I'm myself again—a somewhat hornier person, however. Luckily, I have a partner who likes to flirt. We always have lots of sex, especially since his most recent course. I guess he likes it when I take the initiative more, and demand sex. I'm going to have a shower soon. Then I'll molest my partner. It was almost difficult to look at him in the gym—so huge and sweaty. 


\section{(DemandingLady)}

Thoughts about training schedules and the use of drugs to enhance the results of the training are mixed with different forms of affirmations of the sexual and potent body (cf., Boepple et al. 2016). Side-effects and the fear of masculinisation are now far away; instead, we see a clear celebration of the fitness doping lifestyle and what are seen as positive effects of the drugs. There is no shame or shyness present, but rather a positive affirmation of sexuality and desires. DemandingLady continues:

Spectacular! I came, again, and again and again ... It's usually easy for me to come, but this was quite ridiculous, so damned intense, too.

(DemandingLady)

Descriptions of strenuous training schedules and doping procedures are mixed with almost pornographic descriptions of explicit sexual acts. Although far from all women are as explicit as DemandingLady, the women's subjectivity and desires are expressed in an explicit and straightforward way. Experiencing radical changes and transformations of the body, the women exhibit an affirmation of their desires and lust, which is sometimes embraced (as above) and sometimes tried to be dealt with using "anti-horney pills", as previously described by the username Happy. The women embracing the side-effects of heightened sexual lust and activity can here be understood in terms of a potensification process through which a liminal position is gradually explored and a heightened sense of being in the lived, active and sexual body is developed (cf., Richardson 2008).

\section{Conclusions}

As part of the gym and fitness culture, Monaghan (2002) describes a new ethnopharmacology as an interest in and experimentation with supplements and drugs to achieve the desired body. The ethnopharmacological stock of knowledge derives largely from the subculture of bodybuilding and includes theories of drug use, methods of drug use, and awareness and management of unwanted side-effects (Monaghan 2012). As shown in this article, various Internet forums can, like other social media, provide potential platforms for disseminating such ethnopharmacological knowledge to a wider audience than the audiences found in the subcultural settings of competitive bodybuilding.

In doping discussions on Flashback, men are in the majority and experience from a male perspective and focusing on the male body is hegemonic. The somewhat derogatory concept of broscience can be seen as a part of the broader ethnopharmacological knowledge production and subculture found on Flashback, where men share their personal experiences and ideas about doping, gender and other things, in interaction primarily with other men. In this context, there is also a certain level of mistrust expressed towards medical expertise. The personal and lived experience (of men) is paramount and is taken as self-evident. As a concept, broscience is male-coded, and in a context in which fitness doping is strongly associated with muscle and masculinity, structures of hegemonic masculinity are evident.

Community members on Flashback are not exclusively men, however. Women are also showing an interest in fitness doping and are searching for and disseminating information through the forum. At the same time, what we have seen is how the women seemingly feel required to adapt their questions to a male norm. Since almost all information found in the discussions is written for and based on the male body, the male perspective provides a lens through which the women are obliged to look, and then recalculate dosages, adjust preparations and analyse potential risks of side-effects.

Although men tend to question women's ethnopharmacological knowledge, the imposition of women's experiences and biology contribute to the unlocking of the male hegemony, paving the way for a women's ethnopharmacology. Knowledge based on and for the male body is not sought by women. Instead, advice from other women with first-hand experience, or information from men with girlfriends who have experience with doping, is sought. Based on this approach, new positions and knowledge distribution emerge in which women discuss potentiality and potency in reference to female biology, based on their own experiences. Consequently, this new liminal space opens the door to experimentation and new ways of constructing gendered identities. 
Looking at our findings, it is clear that women incorporate risk management issues concerning health and the development of certain lifestyles, in relation to normative conceptions of femininity and the meaning of womanhood (cf., Boyle 2005). As demonstrated, several women describe a fear that the drugs will trigger a process of masculinisation. In milder forms, however, these effects are partially recoded: a darker voice becomes a sexy voice at risk of becoming a man's voice. Although a hazardous and risky practice, what we see is not only the gradual development of a 'sis science' of fitness doping ethnopharmacology, but also new ways of making gender in the liminality of male-connoted practices. In addition, we also observe the potency of women's efforts to change the body, beyond fixed and stereotypical gender configurations.

Author Contributions: Conceptualization, funding acquisition, supervision J.A.; formal analysis, investigation, writing—original draft E.S., methodology, E.S., T.J.; writing—review \& editing J.A., T.J. All authors have read and agreed to the published version of the manuscript.

Funding: This research was funded by the Swedish Research Council for Health, Working Life and Welfare (FORTE) grant number 2017-01572.

Conflicts of Interest: The authors declare no conflict of interest.

\section{References}

Adler, Patricia, and Peter Adler. 2011. The cyber worlds of self-injurers: deviant communities, relationships, and selves. Symbolic Interaction 31: 33-56. [CrossRef]

Andreasson, Jesper, and Johansson Thomas. 2016. Online doping: The new self-help culture of ethnopharmacology. Sport in Society: Cultures, Media, Politics, Commerce 19: 957-72. [CrossRef]

Andreasson, Jesper, and Johansson Thomas. 2020. Fitness Doping. Trajectories, Gender, Bodies and Health. Chamstoke: Palgrave Macmillan.

Aoki, Doug. 1996. Sex and muscle. The female bodybuilder meets Lacan. Body \& Society 4: 59-74.

Aspers, Patrick. 2011. Etnografiska Metoder: Att Förstå Och Förklara Samtiden [Ethnographic Methods. To Understand and Explain the Contemporary]. Malmö: Liber.

Bates, Geoff, and Jim McVeigh. 2016. Image and Performance Enhancing Drugs: 2015 Survey Results. Liverpool: Liverpool John Moores University.

Belenko, Steven, Karen L. Dugosh, Kevin Lynch, Amy A. Mericle, Michele Pich, and Robert F. Forman. 2009. Online illegal drug use information: An exploratory analysis of drug-related website viewing by adolescents. Journal of Health Communication 14: 612-30. [CrossRef]

Berg, Martin. 2015. Netnografi: Att Forska om och Med Internet [Netnography. To do Research on and with Internet]. Lund: Studentlitteratur.

Bertilsson, Jon. 2014. Netnografi. En metod för att studera internetbaserad kommunikation [Netnography. A method to study internet based communication]. In Kvalitativa Metoder i Strategisk Kommunikation [Qualitative Methods in Strategical Communication]. Edited by Jörgen Eksell and Åsa Thelander. Lund: Studentlitteratur.

Bilgrei, Ola Rø. 2018. Broscience: Creating trust in online drug communities. New Media and Society 20: $2712-27$. [CrossRef]

Blackman, Lisa. 2008. The Body. Oxford: Berg.

Boepple, Leah, Rehanna N. Ata, Ruba Rum, and Joel Kevin Thompson. 2016. Strong is the new skinny: A content analysis of fitspiration websites. Body Image 17: 132-35. [CrossRef] [PubMed]

Boyle, Lex. 2005. Flexing the tensions of female muscularity: How female bodybuilders negotiate normative femininity in competitive bodybuilding. Women's Studies Quarterly 33: 134-49.

Breivik, Gunnar, Dag Vidar Hanstad, and Sigmund Loland. 2009. Attitudes towards the use of performance-enhancing substances and body modification techniques. A comparison between elite athletes and the general population. Sport in Society. Cultures, Media, Politics, Commerce 12: 737-54. [CrossRef]

Brennan, Rebekah, John Wells, and Marie-Claire Van Hout. 2017. The injecting use of image and performance-enhancing drugs (IPED) in the general population: A systematic review. Health and Social Care in the Community 25: 1459-531. [CrossRef]

Bunsell, Tanya. 2013. Strong and Hard Women. An Ethnography of Female Bodybuilding. London: Routledge. 
Börjesson, Annica, Nina Gårevik, Marja-Liisa Dahls, Anders Rane, and Lena Ekström. 2016. Recruitment to doping and help-seeking behavior of eight female AAS users. Substance Abuse Treatment, Prevention, and Policy 11: 11. [CrossRef]

Cash, Thomas, and Thomas Pruzinsky. 2002. Body Image: A Handbook of Theory, Research, and Clinical Practice. New York: Guildford Press.

Christiansen, Ask Vest. 2018. Motionsdoping. Styrketræning, Identitet og Kultur [Recreational Doping. Strenght Training, Identity and Culture].. Aarhus: Aarhus Universitetsforlag.

Christiansen, Ask Vest, Anders Schmidt Vinther, and Dimitris Liokaftos. 2017. Outline of a typology of men's use of anabolic androgenic steroids in fitness and strength training environments. Drugs: Education, Prevention and Policy 24: 295-305. [CrossRef]

Connell, Raewyn, and James W Messerschmidt. 2005. Hegemonic masculinity: Rethinking the concept. Gender \& Society 19: 829-59.

Coomber, Ross, Adele Pavlidis, Giseella Hanley Santos, Michael Wilde, Wiebke Schmidt, and Clare Redshaw. 2015. The supply of steroids and other performance and image enhancing drugs (PIEDs) in one English city: Fakes, counterfeits, supplier trust, common beliefs and access. Performance Enhancement and Health 3: 135-44. [CrossRef]

Demello, Margo. 2014. Body Studies: An Introduction. London: Routledge.

Denham, Bryan. 2008. Masculinities in hardcore bodybuilding. Men and Masculinities 11: 234-42. [CrossRef]

Evans-Brown, Michael, Jim McVeigh, Clare Perkins, and Mark A. Bellis. 2012. Human Enhancement Drugs. The Emerging Challenges to Public Health. Liverpool: North West Public Health Observatory.

Flashback. n.d. Flashback forum [website]. Available online: https://www.flashback.org/ (accessed on 9 October 2018).

Garcia, Angela, Alecea Standlee, Jennifer Bechkoff, and Cui Yan. 2009. Ethnographic approaches to the internet and computer-mediated communication. Journal of Contemporary Ethnography 38: 52-84. [CrossRef]

Grogan, Sarah, Ruth Evans, Sam Wright, and Geoff Hunter. 2004. Femininity and muscularity. Accounts of seven women body builders. Journal of Gender Studies 13: 49-61. [CrossRef]

Henning, April, and Jesper Andreasson. 2019. "Yay, Another Lady Starting a Log!": Women's Fitness Doping and the Gendered Space of an Online Doping Forum. Communication \& Sport. , 1-20. [CrossRef]

Hine, Christine M. 2000. Virtual Ethnography. London: Sage.

Jespersen, Marianne Raakilde. 2012. "Definitely not for women": An online community's reflections on women's use of performance enhancing drugs. In Athletic Enhancement, Human Nature and Ethics. Threats and Opportunities of Doping Technologies. Edited by Jan Tolleneer, Sigrid Sterckx and Pieter Bonte. Dordrecht: Springer, pp. 201-18.

Johansson, Thomas. 1998. Den Skulpterade Kroppen. Gymkultur, Friskvård och Estetik [The Sculptured Body. Gym Culture, Wellness and Aesthetics]. Stockholm: Carlsson Bokförlag.

Johansson, Thomas, and Andreas Ottemo. 2015. Ruptures in hegemonic masculinity: The dialectic between ideology and utopia. Journal of Gender Studies 24: 192-206. [CrossRef]

Klein, Allan. 1993. Little Big Men: Bodybuilding, Subculture and Gender Construction. New York: State University of New York Press.

Kozinets, Robert. 2010. Netnography. Doing Ethnographic Research Online. London: Sage.

Kozinets, Robert. 2015. Netnography: Redefined, 2nd ed. London: Sage Publications.

Liokaftos, Dimitris. 2019. Natural bodybuilding: An account of its emergence and development as competition sport. International Review for the Sociology of Sport 54: 753-70. [CrossRef]

McGrath, Shelly, and Ruth Chananie-Hill. 2009. 'Big Freaky-Looking Women'. Normalizing Gender Transgression through Bodybuilding. Sociology of Sport Journal 26: 235-54. [CrossRef]

Monaghan, Lee F. 2001. Bodybuilding, Drugs and Risk: Health, Risk and Society. New York: Routledge.

Monaghan, Lee F. 2002. Vocabularies of motive for illicit steroid use among bodybuilders. Social Science and Medicine 55: 695-708. [CrossRef]

Monaghan, Lee F. 2012. Accounting for Illicit Steroid Use. Bodybuilders' Justifications. In Critical Readings in Bodybuilding. Edited by Adam Locks and Niall Richardson. New York: Routledge, pp. 73-90.

Murguía, Edward, Mellisa Tackett-Gibson, and Ann Lessem. 2007. Real Drugs in a Virtual World: Drug Discourse and Community Online. New York: Lexington Books. 
Personne, Mark, Magnus Ekström, and Maria Iveroth. 2014. 2,4-dinitro-fenol—ett dödligt bantningsmedel [2,4-dinitro-fenol-A lethal slimming agent]. Läkartidningen 111: CSU7.

Rasmussen, Jon, Christian Selmer, Peter Busch Østergren, Karen Boje Pedersen, Morten Schou, Finn Gustafsson, Jens Faber, Anders Juul, and Caroline Kistorp. 2016. Former Abusers of Anabolic Androgenic Steroids Exhibit Decreased Testosterone Levels and Hypogonadal Symptoms Years after Cessation: A CaseControl Study. PLoS ONE 11: e0161208. [CrossRef] [PubMed]

Richardson, Niall. 2008. Flex-rated! Female bodybuilding: feminist resistance or erotic spectacle? Journal of Gender Studies 17: 289-301. [CrossRef]

Roussel, Peggy, and Jean Griffet. 2000. The Path Chosen by Female Bodybuilders: A Tentative Interpretation. Sociology of Sport Journal 17: 130-50. [CrossRef]

Roussel, Peggy, Lee Monaghan, Sophie Javerlhiac, and François Le Yondre. 2010. The metamorphosis of female Bodybuilders: Judging a paroxysmal body? International Review for the Sociology of Sport 45: 103-9. [CrossRef]

Sagoe, Dominic, Cecilie Schou Andreassen, and Ståle Pallesen. 2014. The aetiology and trajectory of anabolic-androgenic steroid use initiation: A systematic review and synthesis of qualitative research. Substance Abuse Treatment, Prevention, and Policy 9: 1-14. [CrossRef]

Smith, Aaron, and Bob Stewart. 2012. Body perceptions and health behaviors in an online bodybuilding community. Qualitative Health Research 22: 971-85. [CrossRef]

Sousa, Daniela, Helena Carmo, Rita Roque Bravo, Félix Carvalho, Maria de Lourdes Bastos, Paula Guedes de Pinho, and Diana Dias da Silva. 2020. Diet aid or aid to die: An update on 2,4-dinitrophenol (2,4-DNP) use as a weight-loss product. Archives of Toxicology. [CrossRef]

Sumnall, Harry, Michael Evans-Brown, and Jim McVeigh. 2011. Social, policy, and public health perspectives on new psychoactive substances. Drug Testing and Analysis 3: 515-23. [CrossRef]

Sveen, Karin. 2000. Det kultiverade Lidandet: En Bok om Kropp och Samhälle [The Cultivated Suffering. A Book about Body and Society]. Göteborg: Daidalos.

Thualagant, Nicole. 2012. The conceptualization of fitness doping and its limitations. Sport in Society: Cultures, Commerce, Media, Politics 15: 409-19. [CrossRef]

Turner, Victor. 1969. The Ritual Process: Structure and Anti-Structure. New York: Cornell University Press.

Van Hout, Marie-Claire, and Evelyn Hearne. 2016. Netnography of Female Use of the Synthetic Growth Hormone CJC-1295: Pulses and Potions. Substance Use E Misuse 51: 73-84.

Van Hout, Marie-Claire, and Joseph Kean. 2015. An exploratory study of image and performance enhancement drug use in a male British South Asian community. International Journal of Drug Policy 26: 860-67. [CrossRef] [PubMed]

Washington, Myra S, and Megan Economides. 2016. Strong Is the New Sexy: Women, CrossFit, and the Postfeminist Ideal. Journal of Sport and Social Issues 40: 143-61. [CrossRef] 